\title{
Which assessment tools address the categories of the Brief ICF Core Set for Hand Conditions?
}

(C) The British Association of Hand Therapists Ltd 2015

Reprints and permissions: sagepub.co.uk/journalsPermissions.nav DOI: $10.1177 / 1758998315586276$ hth.sagepub.com

\section{(S)AGE}

\author{
Lucelle AW van de Ven-Stevens', Sandra Kus ${ }^{2}$, Maud Graff ${ }^{3}$ and \\ Alexander $\mathrm{CH}$ Geurts ${ }^{3}$
}

\begin{abstract}
Introduction: The purpose of this study was to explore whether assessment tools address aspects that are relevant according to the Brief ICF Core Set for Hand Conditions (BICF-CS).

Methods: Assessment tools meant to assess functioning and/or environmental factors in adults with hand conditions were reviewed. MEDLINE and CINAHL databases, previously published reviews, the book Clinical Assessment Recommendations of the ASHT, and websites of assessment tools were used for the content comparison and linking to the 23 categories of the BICF-CS. The updated version of the linking rules was applied by two reviewers.

Results: Forty-six assessment tools, known within the areas of hand therapy and hand surgery, were linked to the 23 categories of the BICF-CS. Regarding Body functions and body structures, the categories that were most frequently addressed were b730 "Muscle power functions," b280 "Sensation of pain," b7/0 "Mobility of joint functions," and s730 "Structure of upper extremity." Regarding Activities and Participation, 8440 "Fine hand use" was addressed mostly and 25 assessment tools (with a total of I46 items) were linked to this category. Regarding Environmental Factors, only one assessment tool was identified that could be linked to two categories. Fifteen points of discussion were encountered in the linking process.

Conclusions: Content comparison of 46 assessment tools revealed that 19 of the 23 categories of the BICF-CS were addressed. The environmental factors were hardly addressed.
\end{abstract}

\section{Keywords}

Hand therapy, outcome assessment, linking, ICF, hand conditions, hand injuries

Date received: 18 February 2015; accepted: 17 April 2015

\section{Introduction}

Persons with a hand injury or hand disorder (i.e., hand condition) may experience impairments, activity limitations, and participation restrictions. A variety of dayto-day activities may be limited, such as self-care and domestic life. In clinical practice, assessment tools are increasingly used to evaluate, for instance, a person's body functions, self-care abilities, and environmental factors, domains that are described in the International Classification of Functioning, Disability, and Health (ICF).

The ICF was introduced in 2001 by the World Health Organization as a means to address human functioning from a biopsychosocial perspective. ${ }^{1}$ It provides a common language for members from various health care professions to describe individual functioning, disability, and health. ${ }^{1}$ According to the ICF, functioning comprises the components "Body Functions" and "Body Structures" as well as "Activities and Participation." The contextual environmental and personal factors are also considered within

'Department of Rehabilitation, Radboud University Medical Centre, Nijmegen, The Netherlands

${ }^{2}$ Department of Medical Informatics, Biometry and Epidemiology, Ludwig-Maximilians-University, Munich, Germany

${ }^{3}$ Department of Rehabilitation, Radboud University Medical Centre, Donders Institute for Cognition, Brain and Behaviour, Nijmegen, The Netherlands

\section{Corresponding author:}

Lucelle AW van de Ven-Stevens, Department of Rehabilitation, Radboud University Medical Centre, 898 PO Box 9101, 6500 HB Nijmegen, The Netherlands.

Email: LvdVen@ergotherapie.nl;

I.vandeven-stevens@home.nl 
the biopsychosocial perspective, although the "Personal Factors" have not yet been classified. Each component is composed of categories and subcategories providing more than $1400 \mathrm{ICF}$ (sub)categories altogether. ${ }^{1}$ To enhance its applicability in clinical practice and research, ICF Core Sets are needed. ${ }^{2}$ ICF Core Sets list certain aspects taken from the entire classification that are relevant for the description of functioning of individuals being treated in specific settings or with specific health problems, such as hand conditions. ${ }^{2,3}$ The Brief and Comprehensive ICF Core Sets for Hand Conditions ${ }^{4}$ have been adopted at the international ICF consensus conference in May 2009. 5,6 During this conference, from a subset of ICF categories based on preparatory studies, 23 experts selected a total of 117 categories for a Comprehensive Core Set and 23 categories for a Brief Core Set: the Comprehensive (CICF$\mathrm{CS}$ ) and Brief (BICF-CS) Core Set for Hand Conditions, respectively. These core sets can serve as a useful tool to guide hand therapists, hand surgeons, rehabilitation physicians, and researchers in the assessment of a patient's functioning and health in both clinical practice and scientific studies.

The BICF-CS and CICF-CS provide an evidencebased selection of functional aspects and environmental factors that should be considered among patients with hand injuries or hand disorders. Thus, these core sets can be used to determine how well available assessment tools address all relevant aspects of human functioning in individuals with hand conditions. The aim of this study was, therefore, to provide content comparison of assessment tools, known within the area of hand surgery and hand rehabilitation, with the 23 categories of the Brief ICF Core Set for Hand Conditions (BICF-CS).

\section{Methods}

\section{Literature review}

For instruments that assess body functions and structures (impairments), activity (limitations), and/or participation (restrictions) information was gathered. The literature concerning assessment tools that address activity (limitations) and participation (restrictions) in patients with hand conditions was systematically reviewed as reported in previous publications. ${ }^{7,8}$ The MEDLINE and CINAHL databases, the book Clinical Assessment Recommendations of the American Society of Hand Therapists, ${ }^{9}$ and (if existent) websites of assessment tools were used to collect more detailed information about the assessment tools such as content descriptions, administration manuals, and scoring forms. Publications already reporting about a particular assessment tool with respect to the ICF were also reviewed. ${ }^{10-16}$

\section{Assessment tools}

Assessment tools included were either observational instruments or questionnaires meant to assess functioning and/or environmental factors in adults with hand conditions. The definitive list consisted of assessment tools that are commonly used in hand conditions and that are sufficiently described in literature. ${ }^{8,9}$ Observational instruments are performance tests and include (1) pegboard tests measuring only fine hand use; (2) instruments measuring only fine hand use by picking up, manipulating, and placing different objects; and (3) instruments measuring single tasks (and fine hand use) by scoring executed tasks. Questionnaires include patient reported outcome measures and questionnaires that can be completed by hand therapist and patient together. Biomedical and laboratory tests, such as X-rays or electromyography, were not considered.

\section{Linking process}

Two independent reviewers (physical therapy students (St.W. and C.G.) who had been trained for this study) applied the updated version of the linking rules to map the content of the included assessment tools to the 23 BICF-CS categories ${ }^{17}$ (Table 1). The decision on the ICF categories to be linked to the items of a certain instrument was based on the description, scoring form, and test manual as well as on the definitions of the ICF categories. ${ }^{1}$ In the first step of the linking process, the content of each item and, if applicable, its response options (response scale) were determined using the standardized linking rules. Item content was referred to as the meaningful concept(s) addressed by a particular item of an assessment tool. ${ }^{17}$ The meaningful concept within each item of every single instrument was then, in the second step, linked to the most specific BICF-CS category. If an item was considered to address more than one meaningful concept or if it was specified by examples, each concept was separately linked to a BICF-CS category. For example, "Button a shirt or blouse" was linked to 2440 Fine Hand Use as well as to $d 5$ Self-Care.

The ICF has a hierarchical structure. Each chapter of the classification consists of first-, second-, and thirdlevel categories - in some chapters even of fourth-level categories - which represent the single units of the classification system. A lower level category provides information in a more precise way, thus, shares the attributes of its higher level category but not vice versa. For example, the category b2 Sensory functions and pain reflects the first (highest) level, b280 Sensation of pain represents the second level, b2801 Pain in body part corresponds with the third level, and b28014 Pain in upper limb corresponds with the fourth level. The CICF-CS consists of more third- and fourth-level 
Table I. Linking rules.

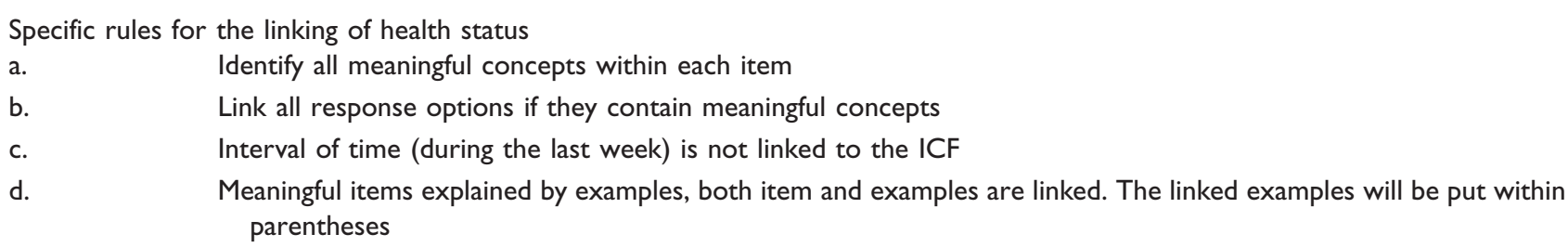

Updated linking rules, to be applied after having used the four specific rules

I. Before one links meaningful concepts, one should acquire knowledge of the conceptual and taxonomical fundaments of the ICF, chapters, domains, and categories of the classification

2. Each meaningul concept is linked to the most precise ICF category

3. Do not use the so-called other specified ICF categories. If the content of a meaningful concept is not named in the corresponding ICF category, the additional information is documented

4. Do not use the so-called unspecified ICF categories, but to the lower level category

5. If the information provided by the meaningful concept is not sufficient for making a decision about the most precise ICF category it should be linked to, the meaningful concept is assigned nd (not definable)

Special cases of this rule:

-Meaningful concepts referring to health in general, physical health or mental health, are assigned: nd-gh, nd-ph or nd-mh (not definable — general health, not definable — physical health, not definable — mental health)

-Meaningful concepts referring to quality of life in general are assigned nd-qol (not definable-quality of life)

6.

If the meaningful concept is not contained in the ICF, but it is clearly a personal factor, it will be assigned as pf (personal factor)

7. If the meaningful concept is not contained in the ICF and it is clearly not a personal factor, it will be assigned as nc (not covered)

8. If the meaningful concept refer to a diagnosis or a health condition, it will be assigned hc (health condition)

Note: ICF, International Classification of Functioning, Disability, and Health.

categories than the BICF-CS. Thus, it was helpful to use the CICF-CS as a reference in the linking process. If needed, a particular assessment tool was first linked to the third- or fourth-level category of the CICF-CS. Then, it was decided whether this tool could be linked to a first- or second-level category of the BICF-CS.

In the case of disagreement between the two reviewers, a third reviewer ( $\mathrm{LvdV}-\mathrm{S})$ was involved to reach consensus. Whenever the reviewers agreed that they were not able to link an item to a BICF-CS category, or whenever their linking differed from that of previous studies, discussion points were noted.

\section{Results}

Regarding all assessment tools, the available information (such as publications, manuals, scoring forms) was sufficient and could be used in the linking process. Table 2 shows the results of this process. Forty-six assessment tools known within the areas of hand surgery and hand rehabilitation could be linked to 19 categories of the BICF-CS. As can be concluded from this table, only 4 of the 23 BICF-CS categories remained unaddressed. These were: $b 810$ "Protective functions of the skin," s120 "Spinal cord and related structures," s720 "Structure of shoulder region," and the environmental factor el "Products and technology." Body Functions most frequently addressed were $b 730$ "Muscle power functions," b280 "Sensation of pain," and 6710 "Mobility of joint functions." Of the Body Structures, only s730 "Structure of upper extremity" was covered. With regard to the component activities and participation, $d 440$ "Fine hand use" was addressed mostly and 25 assessment tools (with a total of 146 items) were linked to this category. The Michigan Hand Outcomes Questionnaire (MHOQ) and the Disabilities of the Arm, Shoulder, and Hand questionnaire (DASH) covered most of the functional aspects of the BICF-CS $(n=14)$ with an almost complete overlap. The only exception was that the MHOQ included "Structure of upper extremity" (s730), whereas the DASH included "Carrying out daily routine" (d230). The categories of the BICF-CS that were not addressed by the DASH or the MHOQ (i.e., b715, b760, b810, s120, s720, e1, e3, e5) were covered only by one (a different instrument per category as can be seen in Table 2) or by no instrument at all. Regarding environmental factors, only the Patient Evaluation Measure (PEM) could be linked to the categories e3 "Support and relationships" and e5 "Services, systems and policies." Fifteen discussion topics were encountered in the linking process (Table 3 ). 


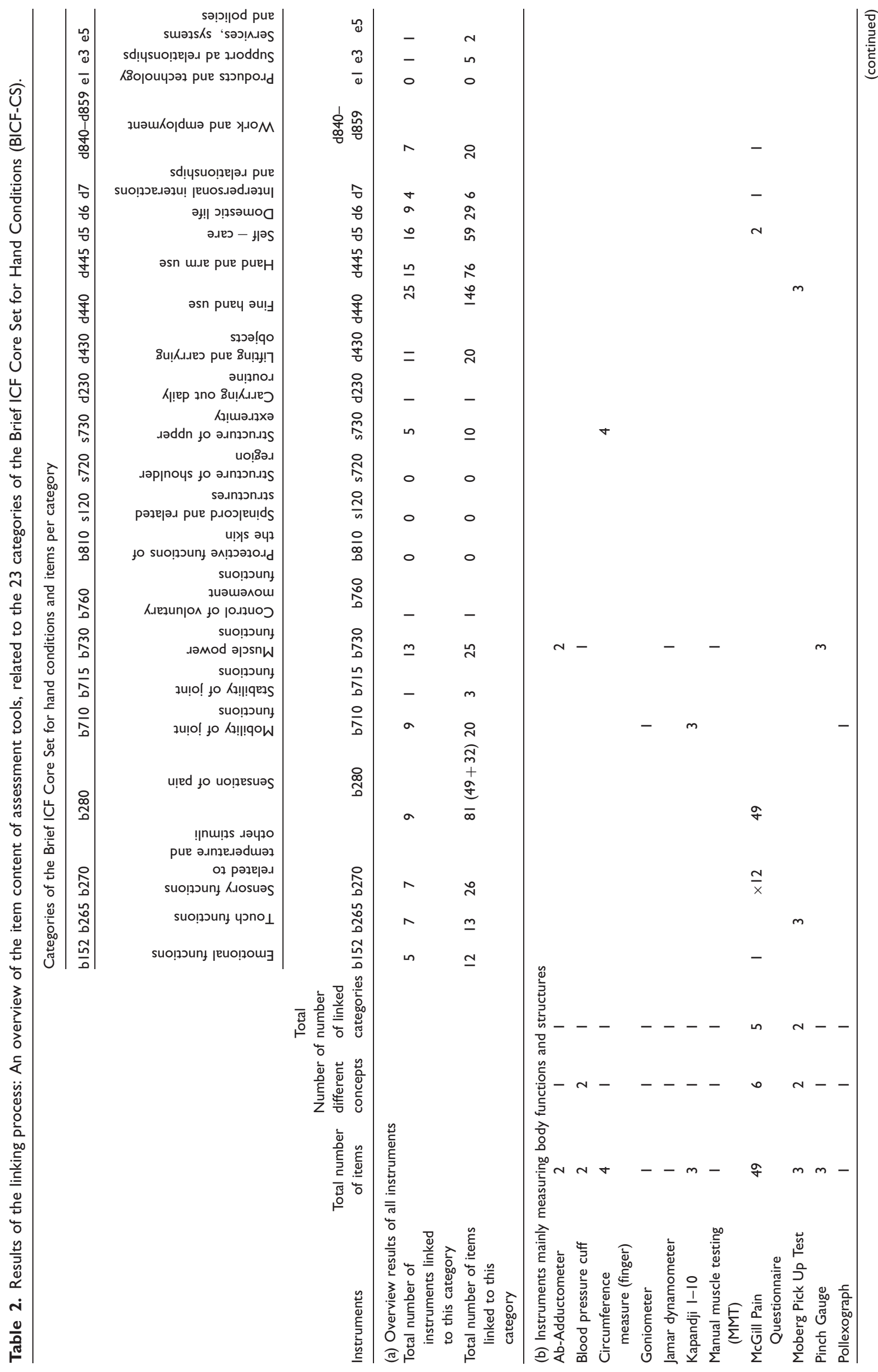




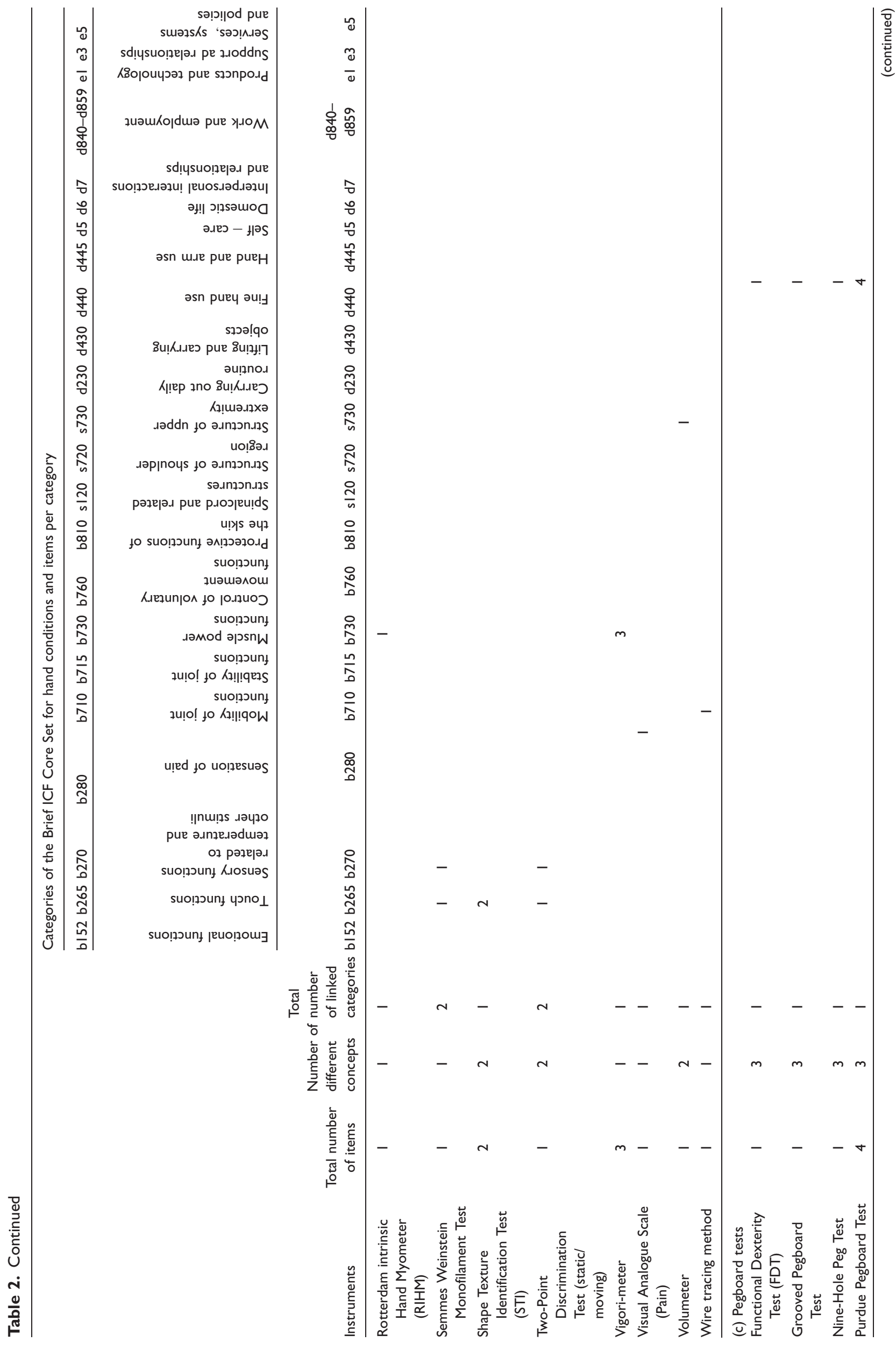




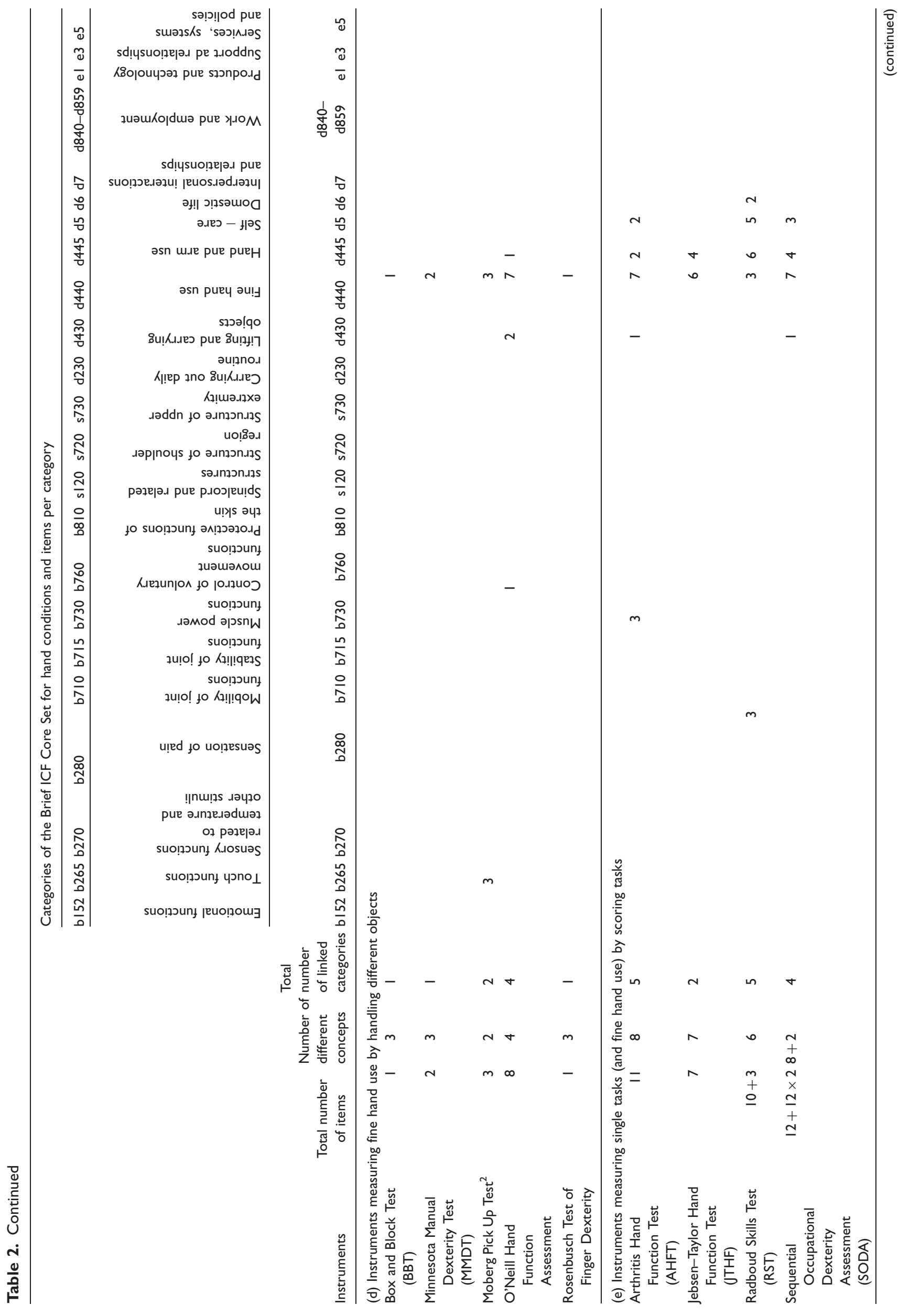




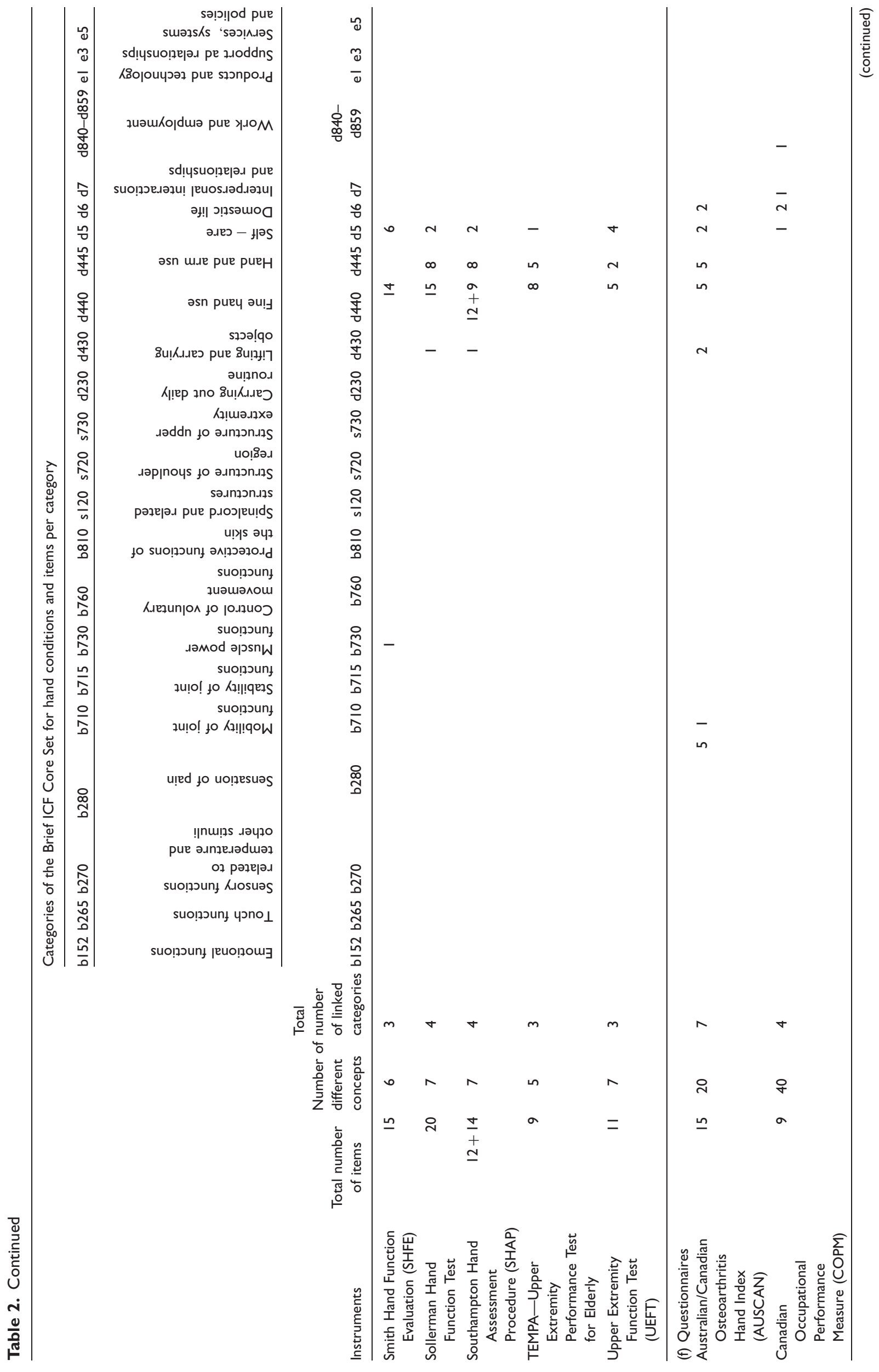




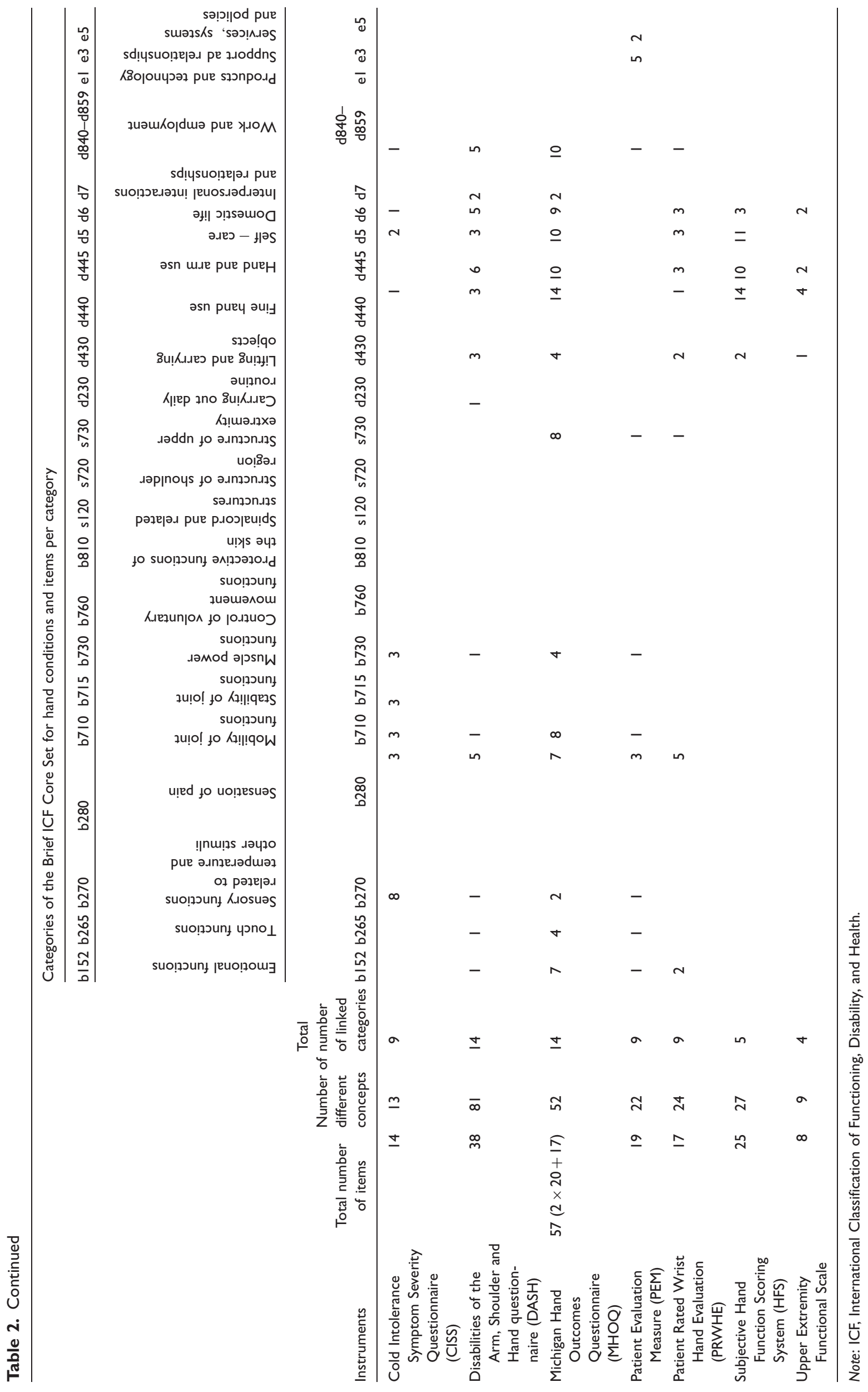


Table 3. Discussion topics among the reviewers being involved in the linking process per category or item.

\begin{tabular}{|c|c|}
\hline Category or construct & Clarification and points of discussion \\
\hline $\begin{array}{l}\text { b7 I0-Mobility of joint functions } \\
\text { and grip strength } \\
\text { measurement }\end{array}$ & $\begin{array}{l}\text { It was discussed whether someone who has maximum muscle power, but does not } \\
\text { achieve the full range of motion, would be able to receive a maximum score } \\
\text { during grip strength measurement. The ICF does not describe clearly if mobility } \\
\text { of joint functions (b7I0) had to be added. It was decided to make a comment on } \\
\text { top of the instrument, to explain that while the main goal of the instrument is } \\
\text { testing the muscle power, one needs mobility to accomplish maximum grip } \\
\text { strength }\end{array}$ \\
\hline $\begin{array}{l}\text { b760, Control of voluntary } \\
\text { movement functions }\end{array}$ & $\begin{array}{l}\text { Control of voluntary movement functions could be added to almost every question } \\
\text { that refers to a function of one's hands or arms. To prevent an extensive linking, } \\
\text { it was decided to link an assessment tool to the category b760 Control of } \\
\text { voluntary movement functions only if the question refers to a very specific task } \\
\text { that requires precise control of the movement }\end{array}$ \\
\hline Cold intolerance & $\begin{array}{l}\text { The specific category b550 I to describe cold intolerance (b550I-maintenance of } \\
\text { body temperature, including cold tolerance) was not included in neither the } \\
\text { Brief nor the Comprehensive ICF Core Set for Hand Conditions. b550I would } \\
\text { be the most accurate choice to describe the functions involved in the main- } \\
\text { tenance of body temperature, which includes heat and cold (in)tolerance. } \\
\text { However, in absence of this category, it was decided to link "cold intolerance" } \\
\text { to b270 (sensory functions related to temperature and other stimuli), as sen- } \\
\text { sitivity to cold came closest to the concept of cold intolerance }\end{array}$ \\
\hline $\begin{array}{l}\text { b8 } 10 \text {-Protective functions of } \\
\text { the skin }\end{array}$ & $\begin{array}{l}\text { Using inspection, one could also evaluate b8/0_protective functions of the skin, as } \\
\text { this category focuses on the forming of callus, ulcers, bedsores, hardening, or } \\
\text { insulating of the skin, which can be seen and evaluated while inspecting the } \\
\text { patient. None of the instruments was linked to this category }\end{array}$ \\
\hline $\begin{array}{l}\text { sI20-Spinal cord and related } \\
\text { structures and b4I5-blood } \\
\text { vessel functions }\end{array}$ & $\begin{array}{l}\text { The category sI } 20 \text { and b4I5 can refer to the underlying cause of the impairments } \\
\text { that are evaluated in several instruments (such as the Carpal Tunnel } \\
\text { Questionnaire or the Semmes-Weinstein Monofilament Test). However, the } \\
\text { spinal cord or blood vessel function itself is not evaluated in these instruments. } \\
\text { Evaluation of the spinal cord would require an MRI or a similar method. s } 20 \\
\text { and b4I5 itself is not linked to any of the instruments if only the consequences } \\
\text { are evaluated }\end{array}$ \\
\hline dI70-Writing & $\begin{array}{l}\text { This is not a Brief ICF Core Set category. The ICF description of dI 70-writing is } \\
\text { "Using or producing symbols or language to convey information" and this cat- } \\
\text { egory is part of chapter I "Learning And Applying Knowledge" of the ICF. In } \\
\text { tests or questionnaires that are used in hand therapy the item "writing" refers to } \\
\text { the skills or dexterity of the hand. As the category d I } 70 \text { writing only covers the } \\
\text { cognitive development of writing, it was decided to link the item "writing" of the } \\
\text { instruments to the category } \mathrm{d} 440 \text { fine hand use in questions about writing }\end{array}$ \\
\hline $\begin{array}{l}\mathrm{d} 230 \text { - Carrying out daily } \\
\text { routine }\end{array}$ & $\begin{array}{l}\text { Because of uncertainties concerning the definition of carrying out daily routine and } \\
\text { its relation to activities of the daily living, both the ICF category description and } \\
\text { the ICF research group were consulted. It was concluded that this ICF category } \\
\text { is concerned with the planning of one's activities rather than with carrying out } \\
\text { the activities themselves. d } 220 \text { Undertaking multiple tasks includes carrying out } \\
\text { the activities. Consequently, those items of the instruments that are concerned } \\
\text { with carrying out activities could not be linked to this category. However, one of } \\
\text { the questionnaires, the DASH, includes one item that focused indeed on the } \\
\text { effect of the injury or problem on the planning of the daily activities and was } \\
\text { therefore linked to this category }\end{array}$ \\
\hline Pegboard test & $\begin{array}{l}\text { Regarding pegboard tests, it was decided to link the category } \mathrm{d} 440 \text { fine hand use } \\
\text { only once per task, independently on how many pegs have to be placed or } \\
\text { removed. The Purdue Pegboard Test contains four different tasks and therefore } \\
\text { is linked to the category } \mathrm{d} 440 \text { four times }\end{array}$ \\
\hline
\end{tabular}


Table 3. Continued

\begin{tabular}{|c|c|}
\hline Category or construct & Clarification and points of discussion \\
\hline $\begin{array}{l}\text { d4402_ grasping versus } \\
\text { d430—-lifting and carrying } \\
\text { objects }\end{array}$ & $\begin{array}{l}\text { It was uncertain to what extent grasping is covered within the category lifting and } \\
\text { carrying objects. Whenever an object can be held in several ways and thus does } \\
\text { not require a developed grasping skill, only the category lifting and carrying } \\
\text { objects was added. Whenever the question described an activity that obviously } \\
\text { required a grasping skill both categories were added }\end{array}$ \\
\hline $\begin{array}{l}\text { d440_Fine hand use (Brief ICF } \\
\text { Core Set) versus } \\
\text { d550_-eating versus } \\
\text { d630_-preparing meals } \\
\text { (Comprehensive ICF Core } \\
\text { Set) }\end{array}$ & $\begin{array}{l}\text { Some difficulties arose concerning linking questions about eating skills. For exam- } \\
\text { ple, it was often asked if someone could accomplish cutting with knife and fork. } \\
\text { It was unclear when it was necessary to link both the categories d440-fine hand } \\
\text { use and d5-selfcare (including eating). It was decided to add fine hand use only } \\
\text { when the question was about the skills that are required to use cutlery } \\
\text { (Arthritis hand function test: cutting with knife and fork). If the question con- } \\
\text { tained words that referred to food, then } \mathrm{d} 5 \text { (eating) and/or } \mathrm{d} 6 \text { (including pre- } \\
\text { paring meals) were also added, depending on whether the question referred to } \\
\text { the preparation of food or its consumption }\end{array}$ \\
\hline $\begin{array}{l}\text { Pouring water: } \mathrm{d} 4453 \text {-Turning } \\
\text { or twisting the hands and } \\
\text { arms versus } \mathrm{d} 440 \mathrm{I} \text {-grasping } \\
\text { versus } \mathrm{d} 560 \text {-drinking (all } \\
\text { categories from the } \\
\text { Comprehensive ICF Core } \\
\text { Set) }\end{array}$ & $\begin{array}{l}\text { Some assessment tools contain questions about pouring water. There was some } \\
\text { doubt concerning the question whether grasping is necessary to pour water. It } \\
\text { was decided that pouring can be accomplished in many ways and does not } \\
\text { always require a developed grasping skill. After all, one can hold a jug in many } \\
\text { ways, and a person without a developed grasping skill is also able to pour water } \\
\text { from a jug. Thus, only turning or twisting the hands and arms was added to } \\
\text { questions which concern pouring. However, already in other studies instru- } \\
\text { ments have been linked and then the category drinking has been added to } \\
\text { questions about pouring. This category was probably linked because pouring can } \\
\text { been seen as a preliminary activity to drinking. However, pouring does not } \\
\text { necessarily lead to drinking. It was decided not to link the category drinking, and } \\
\text { thus d5 Self-care (Brief Core Set), to those questions }\end{array}$ \\
\hline $\begin{array}{l}\text { Not definable (nd) versus spe- } \\
\text { cific activity or fine hand use: } \\
\text { other specified (d4408) }\end{array}$ & $\begin{array}{l}\text { A lot of assessment tools contain questions referring to specific activities or } \\
\text { movements (typing, shaking hands, using tools). It proved to be difficult to } \\
\text { describe those activities or movements using the categories of the Brief or } \\
\text { Comprehensive ICF Core Set. It was decided to use Nd or fine hand use: other } \\
\text { specified to link those items, following the linking rules from Cieza et al. }\end{array}$ \\
\hline $\begin{array}{l}\text { "Swelling"-circumference } \\
\text { measure (finger) and volume } \\
\text { meter }\end{array}$ & $\begin{array}{l}\text { The aspect swelling in arms and hands is not covered by the ICF. Swelling was } \\
\text { linked as not defined However, instruments circumference measure (finger) } \\
\text { and volume meter are linked to s } 730 \text { structure of upper extremity }\end{array}$ \\
\hline $\begin{array}{l}\text { "Recreation and leisure" } \\
\text { (COPM) }\end{array}$ & $\begin{array}{l}\text { Some items could not have been linked to the BICF-CS, for example, the items } \\
\text { including concepts concerning "recreation and leisure," which is included in } \\
\text { d } 920 \text { recreation and leisure of the ICF. This category is not part of the BICF-CS }\end{array}$ \\
\hline $\begin{array}{l}\text { One item scored for right and } \\
\text { left hand }\end{array}$ & $\begin{array}{l}\text { In case I item had to be scored for both the right and the left hand, the specific } \\
\text { category has been linked twice }\end{array}$ \\
\hline
\end{tabular}

Note: BICF-CS, Brief ICF Core Set for Hand Conditions; ICF, International Classification of Functioning, Disability, and Health; DASH, Disabilities of the Arm, Shoulder, and Hand questionnaire; COPM, Canadian Occupational Performance Measure.

\section{Discussion}

This study provides an overview of the item content of 46 assessment tools, known within the area of hand surgery and hand rehabilitation, and compares this content to the 23 categories of the Brief ICF Core Set for Hand Conditions (BICF-CS). The results showed that 19 of the 23 BICF-CS categories were addressed by the included assessment tools.

The area of Activities and Participation was well represented by the various assessment tools. Twentyseven instruments $(60 \%)$ could be linked to one or more categories of this ICF domain. Although this finding suggests that the impact of hand conditions on a broad range of activities of daily living is well addressed clinically, outcome assessments in clinical practice and research focus on body functions rather than on activities and participation. ${ }^{11,12,18,19}$ An explanation for this discrepancy might be that assessment tools such as goniometers or dynamometers are readily available in most clinical settings, whereas instruments to measure activities are less easily available or relatively unknown. Furthermore, only recently, a first consensus was aimed on which assessment tools 
should be used to assess activities and participation in patients with hand conditions. ${ }^{20}$ This could be the reason that these latter assessment tools are not yet implemented in clinical practice and research.

An important additional finding of this study is that environmental factors were hardly addressed by the included assessment tools. From the reviewed instruments, only one instrument captured two of the three environmental factors included in the BICF-CS. The PEM includes several items addressing "medical attention by one or various specialists" and was therefore linked to the categories e3 "Support and relationships" and $e 5$ "Services, systems and policies." According to the biopsychosocial understanding of disability and health, environmental factors dynamically interact with an individual's functioning. ${ }^{1}$ However, it seems that these factors are hardly formally assessed in the current clinical practice of hand therapy. Interventions primarily aim to improve body functions and structures, even though it is important to consider abilities and activities that are relevant to a patient's daily life performance as well. In this context, therapists need to know which environmental aspects (e.g., assistive products, family support, or climate) influence a patient's daily life performance either in a facilitating or in a complicating way. Environmental factors should, therefore, be an integral part of the overall functional assessment. They need to be taken into account in the decisionmaking process with regard to a patient's treatment to provide client-centered care. Thus, more assessment tools should be (developed and) implemented in daily clinical practice that address the impact of an individual's environment on his or her daily life performance.

It is important to realize that the ICF distinguishes two qualifiers (or constructs) for the ICF domain Activities and Participation: "Capacity" and "Performance." Capacity refers to an individual's ability to execute a task or an action in a standardized environment, while performance refers to the activities that an individual executes in his or her daily-life environment. Neither information concerning the extent to which an item refers to activities, to participation, or to both, nor information about whether an item addresses this ICF domain from the perspective of capacity or performance is addressed in the existing linking rules. This might be an aspect of possible improvement of these rules in the future.

Whereas most tests of "Body Functions and Structures" address only one (b- or s-) category, many assessment tools that evaluate "Activities and Participation" address more than one (d-)category. Based on the results of this study, we suggest to use guiding principles for selecting assessment tools as described by Fekete et al. (2011) such as redundancy (the overlap between instruments with respect to underlying ICF categories), efficiency (the number of items that address the domain of interest in relation to the total number of items), level of detail of information (the number of items assessing a single ICF category and the response scale), and feasibility (issues important for researchers and issues relevant for participants). ${ }^{21}$

Although the BICF-CS is very useful for the content comparison of different assessment tools, we encountered several discussion topics per category or item during the linking process (see Table 3 ). In addition, it should be mentioned that many items were linked to d440 "Fine hand use." This ICF category includes third-level categories, such as picking up, grasping, manipulating, and releasing. The BICF-CS does not contain those third-level categories separately, however, to improve discrimination between assessment tools of fine hand use, these third-level categories should be used.

Additionally, it was noticed that in linking items to the ICF, more options can be possible. The number of concepts that was identified for a particular item varied from one to four (e.g., pain, hand/wrist, pain in hand/ wrist, daily activities). Furthermore, it was sometimes unclear whether one or two concepts had to be scored when an item was applicable to both the right and the left hand. Occasionally, it was discussed which concept(s) were applicable. For example, is the item "doing up buttons" referring to fine hand use (d440), to dressing (d5), or to both? In previously published studies ${ }^{15,16,22}$ comparable uncertainties arose. In a content comparison of clinical, occupation-based instruments, the Functional Dexterity Test (FDT) and the Jebsen-Taylor Hand function Test (JTHT) were differently linked to the ICF. ${ }^{16}$ For the FDT only one time score has to be noted that is needed to pick up, manipulate, and release 16 pegs on a pegboard. The JTHT also contains several items that include the scoring of time needed to pick up and release a number of objects. As a result, the FDT was linked to d440 (d4400 and d4402) 16 times, whereas the JTHT was linked to d440 (d4400, d4401, and d4402) only once. ${ }^{16}$ Hence, caution must be taken in selecting an assessment tool for clinical practice or scientific research if based only on one study. We, therefore, suggest that the linking rules are adjusted in the future. In addition, linking instruments to the ICF should preferably be done by at least two reviewers.

Another discussion topic mentioned in Table 3 addresses some domains that were missing, such as oedema and cold intolerance. During the consensus conference in 2009, there were some differences in the knowledge of and familiarity with the ICF codes, definitions, and terminology. For example, "Coldintolerance" was seen as being part of "Sensitivity to temperature" by some participants and as part of 
"Thermoregulatory functions" by others. These differences have influenced the categories that were included in the BICF-CS. ${ }^{6}$

Although an ICF Core Set indicates what aspects should be addressed to describe an individual's functioning and which environmental factors should be considered, some category definitions might be complemented, for example "b265-Touch functions" and "b270-Sensory functions related to temperature and other stimuli" which might include terms such as "stereognosis" and "threshold detection." In addition, to apply an ICF Core Set in clinical practice, it needs to be defined how its aspects should be assessed. As an ICF Core Set refers to a classification system, it does not provide this information. 5,6

The most adequate assessment tools to address individual functioning and environmental factors in patients with hand conditions have not yet been determined. ${ }^{20,23}$ Consequently, there is no standardized or universally accepted core set of assessment tools to be used in hand surgery or hand rehabilitation. ${ }^{7,24-28}$ Since professionals are stimulated to make use of the same assessment tools, reliable and validated instruments to assess (and preferably predict) patients' functioning and to evaluate outcomes of different interventions are required. The increasing number of instruments developed during the last decades has made it difficult to select the best tools, however, the results of the present study can be used in a consensus process to determine which instruments should be used.

\section{Strengths and limitations}

This is the first study to relate the item content of 46 assessment tools that are available to assess body functions and structures as well as activities and participation in patients with hand conditions to the 23 categories of the BICF-CS. The applied method adhered to the updated version of the ICF linking rules. On the other hand, the results highlight some points of discussion in applying these rules and, thus provide indications for their improvement. Some differences between the present results and those of other studies may be due to differences in the interpretation and application of the linking rules. In addition, the assessment tools in this study were linked to the BICF-CS for hand conditions and not, as in other studies, to the ICF itself. As a consequence, some concepts might have been linked to another level category (e.g., second instead of third or fourth level) in comparison with other studies. Another methodological limitation is that this study only used information written in the English, German, and Dutch languages, discarding assessment tools published in other languages. Lastly, we restricted ourselves to the analysis of item content independent of the psychometric properties of the included instruments. This latter aspect has been investigated for instruments assessing activities and participation in previous work of our group. ${ }^{7}$ This clinimetric review revealed that none of the 23 instruments had satisfactory results for all clinimetric properties according to the quality criteria. This means that therapist should be aware that selecting assessment tools based only on the content comparison in this study might still result in the collection of unreliable or invalid data. Thus, further improvement of existing instruments or development of new instruments is needed to cover all the clinimetric properties needed for valid and reliable assessments in patients with hand conditions.

\section{Conclusion and recommendations}

This study has related the item content of 46 assessment tools within the area of hand surgery and hand rehabilitation to the 23 categories of the BICF-CS for hand conditions. The results can support decisions on which instruments are most appropriate for assessing human functioning and environmental factors in patients with hand conditions, taking into account test properties such as redundancy, efficiency, level of detail, and feasibility. The results of this ICF linking study are currently used in a European Delphi study of the HandARTHand Assessment Recommendations for Therapy project. ${ }^{22}$ The aim of this project is to reach European consensus on the selection of a core set of assessment tools to assess "Body Functions and Structures" and "Activities and Participation" in patients with hand conditions according to the BICF-CS.

\section{Acknowledgements}

The authors acknowledge Sacha ten Wolde and Charlotte Gruben for their contribution to this study.

\section{Funding}

This research received no specific grant from any funding agency in the public, commercial, or not-for-profit sectors.

\section{Conflict of interest}

None declared.

\section{References}

1. World-Health-Organization. ICF: International Classification of Functioning Disability and Health. Geneva: World Health Organization, 2001.

2. Stucki G and Grimby G. Applying the ICF in medicine. J Rehabil Med 2004; Jul;(44 Suppl): 5-6.

3. Cieza A, Ewert T, Ustun TB, et al. Development of ICF Core Sets for patients with chronic conditions. J Rehabil Med 2004; (44 Suppl): 9-11. 
4. ICF Research Branch. ICF Core Set for Hand Condition (Brief and Comprehensive), http://www.icf-researchbranch.org/icf-core-sets-projects/other-health-conditions/ development-of-icf-core-sets-for-hand-conditions.html, 2010.

5. Rudolf Klaus-Dieter, Sandra Kus, Michaela Coenen, et al. Report on the International ICF Consensus Conference on the ICF core sets for hand conditions. Hand Therapy 2010; 15: 73-76.

6. Rudolf KD, Kus S, Chung KC, et al. Development of the International Classification of Functioning, Disability and Health core sets for hand conditions - results of the World Health Organization International Consensus process. Disabil Rehabil 2012; 34: 681-693.

7. Ven-Stevens van de LA, Munneke M, Terwee CB, et al. Clinimetric properties of instruments to assess activities in patients with hand injury: a systematic review of the literature. Arch Phys Med Rehabil 2009; 90: 151-169.

8. Ven-Stevens van de L, Munneke M, Spauwen PHM, et al. Assessment of activities in patients with hand injury: a review of instruments in use. $\mathrm{Br} J$ Hand Ther 2007; 12: 4-14.

9. Casanova JS (ed). Clinical assessment recommendations. 2nd ed. Chicago: American Society of Hand Therapists, 1992.

10. Fairbairn K, May K, Yang Y, et al. Mapping PatientSpecific Functional Scale (PSFS) items to the International Classification of Functioning, Disability and Health (ICF). Phys Ther 2012; 92: 310-317.

11. Jerosch-Herold C, Leite JC and Song F. A systematic review of outcomes assessed in randomized controlled trials of surgical interventions for carpal tunnel syndrome using the International Classification of Functioning, Disability and Health (ICF) as a reference tool. $B M C$ Musculoskelet Disord 2006; 7: 96.

12. Kus S, van de Ven-Stevens LA, Coenen M, et al. What is our knowledge of functioning and disability in hand conditions based on? Arch Phys Med Rehabil 2011; 92: 1326-1332.

13. Noonan VK, Kopec JA, Noreau L, et al. Comparing the content of participation instruments using the international classification of functioning, disability and health. Health Qual Life Outcomes 2009; 7: 93.

14. Squitieri L, Reichert H, Kim HM, et al. Application of the brief international classification of functioning, disability, and health core set as a conceptual model in distal radius fractures. J Hand Surg Am 2010; 35: 1795-1805.

15. Stamm T, Geyh S, Cieza A, et al. Measuring functioning in patients with hand osteoarthritis - content comparison of questionnaires based on the International Classification of Functioning, Disability and Health (ICF). Rheumatology (Oxford) 2006; 45: 1534-1541.
16. Stamm TA, Cieza A, Machold KP, et al. Content comparison of occupation-based instruments in adult rheumatology and musculoskeletal rehabilitation based on the International Classification of Functioning, Disability and Health. Arthritis Rheum 2004; 51: 917-924.

17. Cieza A, Geyh S, Chatterji S, et al. ICF linking rules: an update based on lessons learned. J Rehabil Med 2005; 37 : 212-218.

18. MacDermid JC. Measurement of health outcomes following tendon and nerve repair. J Hand Ther 2005; 18: 297-312.

19. Gummesson C, Atroshi I and Ekdahl C. The quality of reporting and outcome measures in randomized clinical trials related to upper-extremity disorders. J Hand Surg Am 2004; 29: 727-734.

20. Ven-Stevens van de LAW, Linde H van der, Selles RW, et al. Which instruments should be used to assess impairments and activity limitations in patients with hand conditions: the HandART Delphi study. Congress of the European Federation of Societies for Hand Therapy, Paris, France, 2014.

21. Fekete C, Boldt C, Post M, et al. How to measure what matters: development and application of guiding principles to select measurement instruments in an epidemiologic study on functioning. Am J Phys Med Rehabil 2011; 90: S29-S38.

22. Drummond SA, Ferreira Sampaio R, Cotta Mancini M, et al. Linking the disabilities of arm, shoulder, and hand to the International Classification of Functioning, Disability, and Health. J Hand Ther 2007; 20: 336-343.

23. Ven-Stevens van de LA, Graff M, Spauwen PHM, et al. HandART: Hand assessment recommendations for therapy, oral presentation. Congress of the European Federation of Societies for Hand Therapy, Oslo, Norway, 2011.

24. Amadio PC. Outcome assessment in hand surgery and hand therapy: an update. J Hand Ther 2001; 14: 63-67.

25. Bucher $\mathrm{C}$ and Hume KI. Assessment following hand trauma: a review of some commonly employed methods. Br J Hand Ther 2002; 7: 79-84.

26. Cano SJ, Browne JP, Lamping DL, et al. The patient outcomes of surgery-hand/arm (POS-Hand/Arm): a new patient-based outcome measure. J Hand Surg [Br] 2004; 29: 477-485.

27. Dowrick AS, Gabbe BJ, Williamson OD, et al. Outcome instruments for the assessment of the upper extremity following trauma: a review. Injury 2005; 36: 468-476.

28. Heras PC, Burke FD, Dias JJ, et al. Outcome measurement in hand surgery: report of a consensus conference. Br J Hand Ther 2003; 8: 70-80. 